\title{
Aulas de educação física e inclusão: um estudo de caso com a deficiência física
}

\author{
Luciana Erina Palma* \\ Greice Rosso Lehnhard**
}

\section{Resumo}

Este estudo teve como objetivo descrever a participação de um aluno com deficiência física em aulas de Educação Física em uma turma do $2^{\circ}$ ano do Ensino Fundamental de uma escola regular. Foram observadas sete aulas de Educação Física da turma, as informações foram registradas em uma Ficha de Observação e, posteriormente, foi aplicada uma entrevista com roteiro pré-estabelecido ao aluno com deficiência. Os dados foram analisados a partir de duas categorias: a) Aluno com Deficiência e a Participação nas Aulas de Educação Física e b) O Relacionamento entre aluno com Deficiência e Colegas. A partir dos dados observou-se que a maioria das atividades propostas pela professora nas aulas de Educação Física favoreceu a inclusão do aluno que possuía deficiência física, além disso, houve interação entre ele e os colegas. Sendo assim, podemos afirmar que a inclusão está sendo efetivada na turma e nas aulas de Educação Física pesquisadas.

Palavras-chave: Educação Inclusiva. Inclusão. Educação Física. Deficiência Física.

\section{Lessons of physical education and inclusion: a case study with physical disabilities}

\section{Abstract}

This study aimed to describe the participation of a student with physical disability in physical education classes of a 2nd year elementary school in a regular school. We observed seven physical education classes, the information was recorded on an observation form and later was applied an interview with preestablished guidelines to disabled student. The datas were analyzed from two categories: a) Students with Disabilities and Participation in Physical Education classes and $b$ ) the relationship between student with Disabilities and Colleagues. From the data, it was observed that most of the activities proposed by the teacher in physical education classes, favored the inclusion of the students who had physical disabilities, in addition to that, there was an interaction between him and his classmates. Thus, we can affirm that inclusion is being accomplished in the classroom and in physical education classes surveyed.

Keywords: Inclusive Education. Inclusion. Physical Education. Physical Disabilities.

\footnotetext{
* Professora Doutora do Departamento de Métodos e Técnicas Desportivas do Centro de Educação Física e Desportos da Universidade Federal de Santa Maria (UFSM). Santa Maria, Rio Grande do Sul, Brasil.

** Especializanda em Atividade Física, Desempenho Motor e Saúde e Educação Física Escolar pelo Centro de Educação Física e Desportos da Universidade Federal de Santa Maria (UFSM). Santa Maria, Rio Grande do Sul, Brasil.
} 


\section{Introdução}

Em 1994, foi assinada a Declaração de Salamanca, o marco da transição do modelo integrativo para o inclusivo (RODRIGUES, 2003; SASSAKI, 2005; SÁNCHEZ, 2005). Enquanto a integração consiste em aceitar a pessoa com deficiência na condição de que ela tenha a capacidade de adequar-se aos procedimentos comuns no trabalho, na escola e na sociedade, a inclusão é a modificação da sociedade como um todo para receber a pessoa com deficiência, gerando seu desenvolvimento e garantindo a cidadania (SASSAKI, 2005).

A Escola Inclusiva passou a ser defendida no intuito de oportunizar a educação de qualidade para alunos com Necessidades Educacionais Especiais (NEE) no ensino regular. Partindo deste princípio, a escola deve atender às mais peculiares necessidades de cada aluno, tendo ele deficiência ou não (SÁNCHEZ, 2005).

Segundo Laplane (2006), a tentativa de tornar a educação acessível a todos, entra em choque com a rigidez do sistema educacional, com a tendência à homogeneização e com a preocupação em atingir um alto desempenho.

Dutra, Silva e Rocha (2006) colocam a formação dos professores como o ponto de partida para caracterizar a escola inclusiva. E ainda, o professor tem o importante papel de preparar os alunos para conviverem com a heterogeneidade, e é justamente a diferença que propicia a troca de experiências e o aprendizado.

Os alunos com NEE, segundo a Política Nacional de Educação Especial na Perspectiva da Educação Inclusiva, são os que tem deficiência (intelectual/cognitiva, física, sensorial ou múltipla), Transtornos Globais do Desenvolvimento e Altas Habilidades. Neste estudo, será abordada apenas a deficiência, mais especificamente a deficiência física, levando em conta os sujeitos nele envolvidos. As pessoas com deficiência são as que possuem impedimentos de longo prazo, sejam eles físicos, mentais ou sensoriais (BRASIL, 2007).

A deficiência física, de acordo com Diehl (2006), é caracterizada por algum tipo de "comprometimento para a realização dos padrões motores esperados" (p. 92), dentre os movimentos que podem vir a ser afetados estão: "caminhar, correr, saltar, manipular coordenadamente objetos e movimentos de estabilização do corpo" (p. 92).

Dentre as deficiências físicas está a Paralisia Cerebral, forma de deficiência apresentada pelo aluno participante do estudo, que se trata de uma lesão no Sistema Nervoso Central que afeta o encéfalo antes de seu pleno desenvolvimento (DIEHL, 2006 e TUDELLA, 2002). Tudella (2002) coloca que essa deficiência pode provocar "alterações do tônus (por exemplo, espasticidade), da postura, da coordenação e controle dos movimentos e das reações posturais (equilíbrio, retificação corporal e defesa)" (p. 164). 
Quando um aluno com deficiência física participa das aulas de Educação Física o professor deve proporcionar ao mesmo, a maior mobilidade possível e de forma autônoma, incentivando sua atuação no meio e comunicação com os colegas (NEBRERA, 2009).

Em estudo realizado por Gomes e Barbosa (2006) acerca da inclusão de alunos com Paralisia Cerebral, constatou-se falta de preparo por parte dos professores diante deste processo e da deficiência em específico. Os autores destacam que trata-se de uma deficiência com características muito peculiares e bastante acentuadas, necessitando de conhecimento específico por parte dos professores.

A Educação Física escolar tem o papel de proporcionar o desenvolvimento cognitivo e físico do aluno a partir de vivências corporais, através do jogo, da dança, das lutas e dos esportes. Para os alunos com deficiência, as adaptações são importantes a fim de que todos participem com as mesmas oportunidades de movimento respeitando suas limitações (STRAPASSON e CARNIEL, 2007). Nebrera (2009) ainda coloca que é muito importante o professor conhecer seu aluno com deficiência física a fim de proporcionar uma educação de qualidade.

No que diz respeito à inclusão de alunos com deficiência em aulas de Educação Física, Lopes e Nabeiro (2008) constataram, a partir de uma pesquisa realizada em uma turma onde um aluno com deficiência estava matriculado, que os colegas reagem positivamente ao processo inclusivo, declarando que colaboram com o colega com deficiência e que o mesmo não atrapalha o andamento da aula e dos conteúdos.

Ainda, Lehnhard, Palma e Antunes (2011), em pesquisa acerca da inclusão de um aluno com deficiência física em aulas de Educação Física, verificaram que o processo de inclusão está ocorrendo, todavia ainda necessita-se de mais interações entre os alunos no sentido de efetivar a educação inclusiva.

De maneira geral, a maioria das pesquisas sobre a inclusão refere-se à opinião de professores, coordenadores e diretores em relação à participação e/ou presença dos alunos com deficiência na escola. Este estudo teve como objetivo descrever a participação de um aluno com deficiência física em aulas de Educação Física em uma escola da rede regular de ensino, levando em conta as atividades realizadas e a opinião do próprio aluno que possui deficiência.

\section{Metodologia}

O grupo foi composto por vinte e cinco (25) alunos de uma classe regular do $2^{\circ}$ ano do Ensino Fundamental de uma escola pública estadual do RS. Um deles possuía deficiência física, especificamente a Paralisia Cerebral. $O$ aluno tinha nove (09) anos, estava matriculado na escola há três (03) anos, mas ainda não estava alfabetizado, participava de um projeto de estimulação essencial motora 
aquática para crianças com deficiência, andava com o auxílio de colegas ou professores, utilizando uma órtese nos membros inferiores e tinha certa facilidade para comunicar-se verbalmente, apenas falando pausadamente.

As aulas de Educação Física ocorreram duas vezes na semana, com duração entre 15 e 30min, os espaços utilizados eram o pátio, a pracinha de brinquedos e a sala de aula, as professora utilizavam materiais variados como bolas, balões, cones, cordas e aros. A maioria das atividades acontecia em grupo nas dependências da escola.

Para a coleta de dados foram utilizados dois instrumentos baseados em Cassiano e Gomes (2003). O primeiro foi uma Ficha de Observação das aulas de Educação Física, contendo itens a respeito das atividades como: se favoreceu a inclusão, como o aluno com deficiência física participava (sozinho, com auxílio de um aluno, com auxílio do professor, com auxílio do grupo todo, não participou ou apenas auxiliou o professor) e a relação entre os alunos durante as atividades (com todos, com alguns, somente com um ou não houve), foi considerado relacionamento entre os alunos os momentos em que eles interagiam por meio de conversas ou durante a realização de atividades. O segundo foi uma entrevista, aplicada ao aluno com deficiência física, com roteiro semi-estruturado, contendo perguntas como: se o aluno gostava das aulas de Educação Física, se conhecia seus colegas, se participa de todas as atividades, quais gostava e quais não gostava e se acreditava que a Educação Física era importante.

Foram observadas sete (07) aulas de Educação Física da turma selecionada, no intuito de verificar a participação do aluno com deficiência nas atividades. As observações foram realizadas por uma pesquisadora, sendo do tipo participante, onde o observador estava presente no ambiente de coleta (GIL, 2006). Ao final das sete (07) observações, foi aplicada uma entrevista ao aluno com deficiência física, a entrevista foi realizada na sala de recursos da escola, foi utilizado um gravador de voz, após a gravação houve a transcrição da mesma.

Os dados foram analisados através de duas categorias de análise sugeridas a partir da ficha de observação e do roteiro da entrevista com o aluno. A primeira: a) "Aluno com Deficiência e a Participação nas Aulas de Educação Física"que discute como o aluno com deficiência participava das atividades; e a segunda: b) "O Relacionamento entre Aluno com Deficiência e Colegas" que discute o relacionamento do aluno com deficiência com os demais e o relacionamento do mesmo com os seus colegas.

\section{Resultados e discussão}

Foram observadas sete (07) aulas de Educação Física da turma participante, destas, cinco (05) foram realizadas no pátio da escola e duas (02) em sala de aula e nestas aulas observadas foram realizadas doze (12) atividades. As aulas foram sempre ministradas pela professora estagiária (do curso de magistério) e acompanhadas pela professora titular da turma, já que os profes- 
sores de Educação Física da escola não ministravam aulas para os Anos Iniciais. Em três (03) aulas observadas, as professoras contaram com o apoio da Educadora Especial da escola. A mãe do aluno que possuía deficiência física acompanhou a parte final de todas as aulas, já que sempre buscava o mesmo na escola.

As aulas de Educação Física tiveram duração mínima de 15min e máxima de 30min. Em princípio, as aulas de Educação Física deveriam ser de 30min, no entanto, algumas vezes os alunos não terminavam as atividades propostas em sala de aula e, para finalizá-las, o horário da Educação Física era utilizado.

Durante as observações, percebeu-se que o aluno que possui deficiência física tinha dificuldades de movimentação nos membros inferiores, não utilizava muletas, andador nem cadeira de rodas, mas necessitava do apoio de alguém para locomover-se. Além disso, possuía dificuldades de preensão de objetos pequenos e de controle de alguns objetos.

Em seguida, serão apresentadas as categorias de análise criadas a partir dos instrumentos utilizados.

\section{a. Aluno com Deficiência e a participação nas aulas de Educação Física}

Esta categoria engloba a maneira como o aluno com deficiência participou das atividades de Educação Física e como essas atividades atuaram favorecendo, ou não, sua inclusão. Analisa também como o aluno percebeu sua participação nas aulas.

Nas sete (07) aulas observadas, foram realizadas doze (12) atividades, em oito (08) o aluno com deficiência física participou tendo o auxílio de uma das professoras, em duas (02) não participou, em uma (01) atividade 0 grupo o ajudou, isso inclui alguns colegas, uma das professoras e a mãe do aluno com deficiência física e em uma (01), realizada em sala de aula, auxiliou as professoras.

Seabra Júnior (2006) traz que a metodologia e as ações adotadas pelo professor são decisivas na participação do aluno com deficiência nas aulas e, com isso destaca "a influência da ação docente na participação ou distanciamento dos alunos, nas aulas de Educação Física" (p. 80).

Quando perguntado ao aluno sobre sua participação nas aulas de Educação Física, ele disse que participou de todas as atividades propostas e que gosta muito das aulas, considerando-as muito divertidas ${ }^{1}$. É possível que o aluno entenda presença e participação como sinônimas, acreditando que estar presente na aula, mesmo sem realizar as atividades junto aos colegas, significa estar participando. No entanto, a efetiva participação só se dá quando os alunos compreendem e praticam as atividades propostas, interagindo com colegas e professores. 
A não participação dos alunos em algumas atividades caracterizou a atitude de superproteção por parte da professora da turma, sendo que a mesma temia que o aluno se machucasse, mesmo que uma outra professora da escola sugerisse que os alunos auxiliassem o colega com deficiência. Lima e Silva (2009) colocam que a atitude de impedir que o aluno explore os espaços e movimentos por medo que se machuquem, assinala superproteção que é classificada como barreira atitudinal. As barreiras atitudinais são, de acordo com os autores, "a utilização de rótulos, adjetivações, substantivação da pessoa com deficiência como um todo deficiente" (p.27). Em contrapartida, a professora tinha como responsabilidade, no momento da aula, a integridade física de seus alunos, o que pode justificar seus cuidados com o aluno que possuía deficiência física.

Quando observamos uma pessoa com deficiência, o que chama a atenção é a deficiência, fazendo com que esqueçamos que esses indivíduos também são capazes. Partindo do senso comum, são criados os pré-conceitos de que são seres incapacitados de realizar as atividades corriqueiras como uma pessoa sem deficiência.

A partir do que foi observado, notou-se que o aluno apresentou dificuldades para locomover-se independentemente em função da deficiência, necessitando sempre do apoio de outra pessoa para a realização das atividades. Cidade e Freitas (2002) colocam que alguns alunos com deficiência física podem necessitar de ajuda manual para a realização de algumas atividades, movimentos ou tarefas em função do comprometimento que possuem. Dutra, Silva e Rocha (2006) complementam que ter conhecimento sobre a deficiência do aluno e suas conseqüências é de extrema relevância a fim de adequar sua metodologia.

A partir das observações, das doze (12) atividades realizadas, oito (08) favoreceram a inclusão. Dentre as quais estavam atividades realizadas, em sua maioria, em duplas ou em grupos, atividades que envolviam chutar a bola, passar por aros, manusear balões, desviar obstáculos, rodas cantadas, atividades de memorização e adivinhação.

A inclusão ocorreu porque $o$ aluno estava presente nas atividades e participando destas. Vale reforçar que a participação do aluno pode ser mais efetiva nas aulas, já que em algumas atividades o mesmo não participou.

Como citado anteriormente, o aluno apresenta dificuldades de locomoção e de apreensão de alguns objetos, no entanto, tem potencialidades a serem exploradas e desenvolvidas. Dentre estas potencialidades enfatiza-se aqui a facilidade de lembrar, que poderia ser utilizada em brincadeiras cantadas e em atividades que exijam a memorização de espaços ou movimentos a realizar. Também se cita alguns movimentos como chutar, arremessar ou empurrar que foram empregados em uma atividade realizada com balões em uma das aulas, tarefas estas que o aluno com Paralisia Cerebral realizou com certa facilidade. 
Das doze (12) atividades, quatro (04) não favoreceram a inclusão do aluno com deficiência física. Dentre elas, uma (01) atividade foi realizada na sala de aula em que os alunos deveriam escrever palavras escolhidas pelo colega com deficiência física, e o mesmo atuou apenas como auxiliar da professora e não participou escrevendo. A segunda foi uma atividade em que os alunos deveriam encher e esvaziar balões, a professora encheu o balão e deu para o aluno com deficiência física esvaziá-lo, não dando ao mesmo a oportunidade de enchê-lo. Na terceira a turma brincou livremente pela pracinha da escola e o aluno com deficiência física ficou sentado em uma cadeira, olhando os colegas brincar. Aúltima foi uma roda cantada, da qual o aluno também não participou.

Para que a inclusão ocorra de fato, faz-se necessário, segundo Dutra, Silva e Rocha (2006), que sejam dadas as mesmas oportunidades à todos, independente de sua deficiência. Seabra Júnior (2006) acrescenta que a adaptação das atividades para proporcionar a participação dos alunos na aula, dar orientações durante as atividades e estimular a participação dos alunos caracterizam ações que favorecem a aprendizagem e as interações entre os mesmos.

Em relação a atividade de escrever no quadro, é provável que o aluno com deficiência física apresente dificuldades na realização da tarefa, já que o mesmo não é alfabetizado e possui dificuldades de apreensão, o que dificultava a escrita. Todavia o quadro oferecia condições de acessibilidade ao aluno, tendo altura adequada, ainda, é possível que a professora não quisesse expor a dificuldade do aluno frente aos colegas sem deficiência,

Além disso, não foi dada a oportunidade ao aluno de encher o balão, provavelmente pelo fato de ele apresentar dificuldades na apreensão de objetos pequenos. No entanto, não foram oferecidas ao mesmo, oportunidades de realizar essas atividades e, quando a professora faz a tarefa para ele ou impede que ele a faça, estará tirando uma chance de aprendizado e de participação efetiva.

$\mathrm{Na}$ atividade desenvolvida na pracinha, foram as barreiras arquitetônicas que impediram a participação do mesmo. A pracinha não possui acessibilidade que, de acordo com Manzini (2005), é garantida pela situação da estrutura física nas escolas. A partir da falta de condições de acessibilidade, torna-se impossível que o aluno que possui deficiência física e a conseqüente dificuldade de locomoção, desfrute destes espaços como seus colegas sem deficiência.

O aluno considera as atividades de fácil execução, no entanto, ao ser indagado sobre o que a professora poderia fazer para que sua participação fosse facilitada nas atividades ou mais efetiva, ele disse que gostaria que ela 0 fizesse participar mais.

Através do relato do aluno com deficiência, percebemos que ele sente necessidade de participar mais das atividades nas aulas de Educação Física. Esse fato vai ao encontro das observações realizadas em que, algumas vezes, 
o aluno não participou das atividades em função de suas limitações, principalmente as ocasionadas pela deficiência física, e das limitações impostas pelo ambiente.

\section{b. $O$ relacionamento entre aluno com deficiência e colegas}

A segunda categoria discute o relacionamento do aluno com deficiência com os colegas nas aulas observadas, além de discutir como o aluno visualiza essa relação. No que diz respeito ao relacionamento do aluno com deficiência com os demais, em seis (06) atividades houve relacionamento, em cinco (05) não houve e em uma (01) houve com um (01) colega.

Na entrevista, o aluno com deficiência expôs que conhece todos seus colegas e sabe o nome de alguns, além disso, os considera seus amigos e relatou que os mesmos o ajudam nas aulas. Em estudo realizado por Cassiano e Gomes (2003), com deficiência visual e aulas de Educação Física, os autores notaram, durante a observação das aulas de Educação Física, que a aluna com deficiência procurava relacionar-se com os colegas e conhecia todos, ainda confirmou que os colegas a procuravam, a partir disso concluíram que não havia discriminação na turma pesquisada.

Nas atividades em que alguns alunos procuraram o colega com deficiência física, esse número de alunos foi de dois ou três, uma parte pequena em uma turma com vinte e cinco (25) alunos. O fato de colegas o procurarem é um ponto positivo, demonstrando que o aluno não é rejeitado por estes colegas. A rejeição, para Lima e Silva (2009) caracteriza-se pela recusa da pessoa sem deficiência a interagir com o que a possui e é classificada como uma barreira atitudinal. No entanto, alguns colegas interagiram com o aluno que possuía deficiência física e o mesmo interagiu com aqueles, demonstrando que a turma caminha para a solidificação da inclusão. $O$ fato de ter uma pessoa observandoos pode ter provocado nos alunos atitudes diferentes comparadas às aulas onde não havia um observador, no entanto, o comportamento dos colegas foi constante durante as observações.

Ao realizar um estudo acerca da inclusão escolar de um aluno com deficiência auditiva, Lacerda (2007) traz que o aluno também se sente inserido em sua turma, considera os colegas seus amigos e relaciona-se bem com os mesmos. No entanto, o aluno com deficiência não sabe os nomes de seus amigos e não os identifica por sinais, o que é essencial à identificação das pessoas na Língua Brasileira de Sinais (LIBRAS), além disso, algumas de suas colegas entrevistadas relataram que tem dificuldade de comunicar-se com seu colega e não têm intimidades com ele como têm com os demais alunos da turma.

Tanto o aluno com deficiência física como o com deficiência auditiva mostraram-se satisfeitos com a realidade em que se encontram, Lacerda (2007) considera esta relação muito superficial, mas justifica a satisfação do aluno com deficiência auditiva pelo fato de ele nunca ter tido outra oportunidade de relacionar-se com outros colegas. 
Já Cassiano e Gomes (2003) observaram que a aluna com deficiência visual tem um bom relacionamento com os colegas videntes, isto porque todos os alunos que responderam a entrevista relataram que conhecem a aluna e relacionam-se com ela.

Em estudo realizado por Montilha et al. (2009) acerca da percepção de alunos com deficiência visual sobre a inclusão escolar, $42,3 \%$ destes alunos relataram que o relacionamento com os colegas tinha pouca influência sobre 0 aprendizado, enquanto $69,2 \%$ consideraram que o bom relacionamento com 0 professor influenciava. Porém, é importante que o aluno interaja com um maior número de colegas afim de que os mesmos convivam com a pessoa que possui deficiência no intuito de diminuir e abolir os preconceitos e a discriminação.

Em uma das atividades, realizada em duplas, o colega que estava com o aluno com deficiência física demonstrou preocupação diante da possibilidade de seu colega não conseguir realizá-la, fazendo com que a dupla não fizesse o circuito proposto na mesma velocidade e ritmo que os demais. Esse fato é um dos exemplos da competição que existe na turma, ou seja, os alunos vêem as atividades propostas como competição e o colega com deficiência física poderá de certa forma, atrapalhar o desempenho daquele grupo.

A competição pode aparecer em muitos momentos da vida, por isso a importância de trabalhá-la, é comum que crianças nesta faixa etária queiram sempre concorrer e, de preferência, ganhar. $O$ fato do aluno com habilidades menos desenvolvidas ou o que possui deficiência estar inserido na atividade, poderá vir a "atrapalhar", o que não o fará ser bem aceito pelo grupo. Nestes casos, o educador tem o papel de ensinar que a cooperação também deve existir, a fim de conscientizá-los de que somos todos diferentes e cada um tem seu potencial. No entanto, acredita-se que o aluno foi cooperativo, já que ele auxiliou o colega e compreendeu suas limitações e essa atitude se sobressaiu diante da competição.

Cassiano e Gomes (2003) acrescentam que as atividades em duplas facilitam a execução das atividades e fazem com que os alunos com deficiência não se sintam rejeitados pela turma. Ainda, segundo Oliveira (2002), a inclusão proporciona a transformação da concepção que os alunos têm acerca da pessoa com deficiência, isto porque convivem e aprendem com a heterogeneidade. Além disso, a autora coloca que as aulas de Educação Física devem, a partir de atividades corporais, gerar atitudes de respeito e aceitação.

Dutra, Silva e Rocha (2006) trazem que as mudanças físicas do ambiente não são suficientes para promover a inclusão, são necessárias, principalmente mudanças atitudinais, que dizem respeito aos costumes e posturas das pessoas. Essas atitudes levam as pessoas a ver a deficiência antes mesmo de enxergar a pessoa que a possui como um sujeito com capacidades e potencialidades. Os autores ainda ressaltam a importância de, principalmente 
no ambiente escolar, removê-las assim que forem percebidas a fim de que as mesmas não se perpetuem.

Schenfert (2008) coloca a falta de informação como um "grande gerador de barreiras em toda a sociedade" (p. 33) e traz como conseqüência disso os preconceitos em relação às pessoas com deficiência. Além disso, a "reversão deste quadro reside na educação que direcionamos para as crianças" ( $p$. 33). A autora indica a literatura infantil como um meio de auxílio à transposição das barreiras atitudinais, já que a criança estará aprendendo através do lúdico e da construção do imaginário. De acordo com a autora, esse método já vem sendo utilizado por alguns educadores e têm dado resultados positivos como um meio de favorecer a inclusão.

\section{Considerações finais}

Ao final do estudo, podemos concluir que a inclusão está ocorrendo de forma parcial na turma em questão, especialmente nas aulas de Educação Física. Entendemos esta inclusão como parcial levando-se em consideração que o aluno com deficiência física não participou de todas as atividades desenvolvidas.

Entendendo que as aulas de Educação Física proporcionam uma maior proximidade física dos alunos, o que gera aprendizado em função das trocas que ocorrem entre os mesmos, surge a preocupação de que a disciplina adquira maior importância no ambiente escolar. Ainda, a Educação Física tem como tarefa fazer com que o aluno descubra e desenvolva suas capacidades, o que pode auxiliar no processo inclusivo.

Por fim, destacamos a importância de haver condições de acessibilidade no ambiente escolar e para as aulas de Educação Física, além da relevância do professor estar preparado para o trabalho com alunos com deficiência em todos os momentos da aula.

\section{Referências}

BRASIL. Ministério da Educação Especial. Política Nacional de Educação Especial na Perspectiva da Educação Inclusiva. Distrito Federal, 2007, 15 p.

CASSIANO, F.. GOMES, N. M.. O Deficiente Visual no Ensino Regular, um Estudo de Caso em Aulas de Educação Física. In: MARQUEZINE, M. C.; ALEMIDA, M. A.; BUSTO, R. M.; TANAKA, E. D. O. (Org.). Educação Física, atividades motoras e lúdicas, e acessibilidade de pessoas com necessidades especiais. Londrina: Eduel, 2003.

CIDADE, R. E.; FREITAS, P. S. Educação Física e Inclusão: considerações sobre a prática pedagógica na escola. Integração (Brasília), Brasília, ano 14, p. 26-30, 2002. 
DIEHL, R. M. Jogando com as diferenças: jogos para crianças e jovens com deficiência. São Paulo- SP: Phorte, 2006.

DUTRA, R. S.; SILVA, S. S. M.; ROCHA, R. C. S. A educação inclusiva como projeto da escola: O lugar da educação física. Revista Adapta, ano 2, n. 1, p. 7-12. Rio Claro: UNESP, 2006.

GOMES, C.; BARBOSA, A. J. G. Inclusão escolar do portador de paralisia cerebral: atitudes de professores do ensino fundamental. Revista Brasileira de Educação Especial. v. 12, n. 1. Marília, 2006.

GIL, A. C. Como elaborar projetos de pesquisa. 4. ed. São Paulo: Atlas, 2006.

LACERDA, C. B. F. de. O que dizem/sentem alunos participantes de uma experiência de inclusão escolar com aluno surdo. Revista Brasileira de Educação Especial, Marília, v. 13, n. 2, p. 257-280, mai./ago. 2007.

LAPLANE, A. Uma análise das condições para a implementação de políticas de educação inclusiva no Brasil e na Inglaterra. Educação \& Sociedade. v. 27, n. 96. Campinas, out. 2006.

LEHNHARD, G. R.; PALMA, L. E; ANTUNES, M. R. Participação de Alunos com Deficiência Física nas Aulas de Educação Física. In: XVI Seminário Interinstitucional de Ensino, Pesquisa e Extensão. Anais..., UNICRUZ, Cruz Alta, out. 2011.

LIMA, F. J. de; SILVA, F. T. dos S. Barreiras Atitudinais: Obstáculos à Pessoa com Deficiência na Escola. In: SOUZA, O. S. H. (Org.). Itinerários da inclusão escolar: múltiplos olhares, saberes e práticas. 2009. Disponível em: <http:/ /books.google.com>. Acesso em: jun. 2010.

LOPES, A. de C.; NABEIRO, M. Educação física escolar e o contexto inclusivo: o que pensam os educandos sem deficiência? Motriz, Rio Claro, v. 14 n. 4, p. 494-504, out./dez. 2008.

MANZINI, E. J. Inclusão e Acessibilidade. Revista da Sobama, v. 10, n. 1, Suplemento, p. 31-36. Rio Claro, 2005.

MONTILHA, R. de C. I. et al. Percepções de escolares com deficiência visual em relação ao seu processo de escolarização. Paideia, v. 19, n. 44, p. 333339. set./dez. 2009. Disponível em <http://www.scielo.br/pdf/paideia>. Acesso em: jul. 2010.

NEBRERA, J. J. R. Alumnado com discapacidad motora, respuesta educativa. Revista Digital, Buenos Aires, 2009. Disponível em: <http:www.efdesportes.com>. Acesso em: jul. 2010.

OLIVEIRA, F. F de. Dialogando sobre Educação, Educação Física e Educação Escolar. Revista Digital, Buenos Aires, ano 8, n. 51, ago. 2002. Disponível em: <http:www.efdesportes.com>. Acesso em: maio 2010. 
RODRIGUES, D. A Educação Física perante a Educação Inclusiva: reflexões conceptuais e metodológicas. Boletim da Sociedade Portuguesa de Educação Física. Lisboa: Universidade Técnica de Lisboa. v. 24/25, p. 73-81, Lisboa, 2003.

SÁNCHEZ, P. A. A Educação Inclusiva: um meio de construir escolas para todos no século XXI. Revista Inclusão, ano 1, n. 1, p.19-23. Brasília, out. 2005.

SASSAKI, R. K. Inclusão: o paradigma do século 21. Revista Inclusão. ano 1, n.1, p.19-23, Brasília, outubro de 2005.

SCHENFERT, D. Barreiras Atitudinais e a Inclusão. Monografia apresentada como requisito parcial para a obtenção do titulo de especialista no Curso de Pós-Graduação em Educação Especial do Instituto Brasileiro de Pós-Graduação e Extensão - IBPEX. Curituba, 2008. Disponível em: <http://www.fiepr.org.br/ bibliotecadigital>. Acesso em: maio 2010.

SEABRA JÚNIOR, L. Inclusão, necessidades especiais e Educação Física: considerações sobre a ação pedagógica no ambiente escolar. 2006. Dissertação (Mestrado) - Faculdade de Educação Física, Universidade Estadual de Campinas, Campinas.

STRAPASSON, A. M.; CARNIEL, F. A Educação Física na Educação Especial. Revista Digital, Buenos Aires, ano 11, n. 104, janeiro de 2007. Disponível em: <http:www.efdesportes.com >. Acesso em: maio 2010.

TUDELLA, E. Deficiência Física. In: PALHARES, M. S.; MARINS, S. (Org.). Escola Inclusiva. São Carlos: UFSCar. p. 155-177, 2002.

Nota

1 Palavra utilizada pelo aluno na entrevista.

\section{Correspondência}

Greice Rosso Lehnhard - Rua Coronel Niederauer, n. 1644, ap. 504, CEP:97015-122 - Santa Maria, Rio Grande do Sul, Brasil.

Recebido em 23 de março de 2011

Aprovado em 05 de nobembro de 2011 